\begin{tabular}{|c|c|c|c|c|}
\hline $\begin{array}{c}\text { REVISTA ENTORNO } \\
\text { GEOGRÁFICO }\end{array}$ & $\begin{array}{c}\text { Julio/ } \\
\text { Diciembre } \\
2019\end{array}$ & $\mathrm{~N}^{\circ} 18$ & pp. 1-21 & $\begin{array}{c}\text { ISSN (en línea): 2382-3518/ ISSN } \\
\text { impreso: 1692-0074 }\end{array}$ \\
\hline
\end{tabular}

DOI: $10.25100 /$ eg.v0i18.8595

(C) $(\Theta \Theta$

Espacios y Territorios

\title{
Movilidades cotidianas y nuevos modos de habitar: Un análisis en y desde la periferia metropolitana
}

\section{Daily mobilities and new ways of living: an analysis from and within the metropolitan periphery}

Fabricio Espinosa Ortiz

Doctor en Geografía de la Universidad Nacional Autónoma de México. Premio Internacional de

Tesis de Investigación sobre Vivienda y Desarrollo Urbano Sustentable 2014.

Universidad Nacional Autónoma de México. Ciudad de México Distrito Federal, México.

ORCID: 0000-0001-5414-4366

Correo electrónico: fabespi@gmail.com

Para citar este artículo: Espinosa Ortiz, F. (2019). Movilidades cotidianas y nuevos modos de habitar: Un análisis en y desde la periferia metropolitana. Entorno Geográfico, (18). DOI: 10.25100/eg.v0i18.8595.

Resumen: La distancia cada vez mayor que separa a los habitantes de las periferias metropolitanas de las oportunidades que ofrecen los centros urbanos posiciona a la movilidad cotidiana como un importante elemento de análisis y discusión para la comprensión integral de nuevas formas de habitar la metrópoli. A partir del trabajo de campo, que consistió en entrevistas semiestructuradas, recorridos de observación, y observación participante, el presente artículo analiza experiencias de movilidad cotidiana de habitantes de la periferia metropolitana de Morelia, Michoacán, México. Se argumenta que la movilidad no se limita a los desplazamientos origen/destino, puesto que en la búsqueda de los habitantes por satisfacer sus necesidades y deseos de movilizarse se entremezclan experiencias relacionadas con sus motivos, recursos, y sentidos, que además de conformar estrategias de movilidad moldean nuevos modos de habitar.

Palabras clave: movilidades cotidianas, hábitar politópico, narrativas, periferia metropolitana.

Abstract: The distance that separates the inhabitants of metropolitan peripheries from the opportunities offered in the core city makes daily mobilities an important element 
of analysis to understand new ways of inhabiting metropolitan areas. Based on fieldwork, comprised of semi-structured interviews, site visits, and participant observation, this article analyzes urban mobility experiences in the city of Morelia, Michoacán. It argues that mobility is not limited to inhabitant's origin/destination travels, because in searching of meeting their needs and desires to mobilize, inhabitants,

Recibido: 24 de junio de 2019

\section{INTRODUCCIÓN \\ D} siglo pasado se dio una apertura a las empresas inmobiliarias privadas en la construcción de vivienda de interés social, ${ }^{1} \mathrm{y}$ con ello, una paulatina retirada del Estado mexicano, que fue delegando varios aspectos de su intervención en la vivienda a estas empresas (Puebla, 2002, 2010; Schteingart y Patiño, 2006). Ante esto, los desarrolladores inmobiliarios privados se han convertido en los actores principales de la producción masiva de vivienda en México y han divulgado, con sus potentes discursos de promoción inmobiliaria, la oportunidad de adquirir una vivienda amplia y con buen diseño arquitectónico, y además la posibilidad de mejorar la calidad de vida de

\footnotetext{
1 La vivienda de interés social tiene dimensiones promedio de 40 a $71 \mathrm{~m}^{2}$ y es destinada a la población de bajos recursos en México (SEDATU y CONAVI, 2017, p. 61).

2 Fraccionamiento es la división de un terreno en manzanas y lotes, que requiera del trazo de una o más
}

come up with strategies based on their experiences. These strategies are linked to their motives, resources, and meanings, shaping the mobility strategies, but also molding new ways of living in the metropolis.

Key words: daily mobilities, polytopic inhabiting, narratives, metropolitan periphery.

Aceptado: 27 de septiembre de 2019

sus clientes potenciales, al vivir en un fraccionamiento $^{2}$ seguro, bien localizado, y equipado. Sin embargo, la realidad de la mayoría de quienes adquirieron una vivienda de interés social es otra (Espinosa, 2015; Marosi, 2017; Pedrotti, 2016). Algunas inmobiliarias con la finalidad de reducir costos de producción e incrementar utilidades, construyen viviendas de dimensiones mínimas, con materiales de baja calidad y ubicadas en las periferias metropolitanas, (cada vez más alejadas de las zonas de empleo, abasto, educación, ocio, etc.) en donde el costo del suelo es más bajo. Con ello han dificultado la movilidad cotidiana de sus habitantes, ya que se ven obligados a recorrer largas distancias en la búsqueda por satisfacer sus necesidades $\mathrm{y}$ deseos de movilizarse.

vías públicas, así como la ejecución de obras de urbanización que le presten servicios urbanos (SEDATU y CONAVI, 2017, p. 34). 
Las distancias cada vez mayores que separan los entornos habitacionales periféricos de los centros urbanos, posiciona a la movilidad como un importante elemento de análisis y discusión para la comprensión integral de las nuevas formas de habitar la metrópoli. El entender las experiencias ${ }^{3}$ de la movilidad cotidiana desde las Ciencias Sociales, forma parte del llamado giro de la movilidad que implica problematizar y abordar desde el enfoque del sujeto en movimiento, la complejidad de sus prácticas, de sus relaciones sociales, sus redes y flujos, así como sus relaciones en el espacio y con el espacio en su sentir, percibir y concebir los lugares que transita y habita cotidianamente (Cresswell, 2006, 2010; Sheller, 2017; Sheller y Urry, 2006, 2016; Urry, 2007), lo que puede dar luces a la teoría y práctica del urbanismo (Cresswell, 2006, 2010), y con esto tener elementos para proponer modos de movilidad activos y sustentables, así como intervenciones urbanas destinadas al mejoramiento de la calidad de vida de los habitantes.

En este artículo se analizan experiencias de movilidad cotidiana de habitantes de la periferia metropolitana de Morelia, Michoacán, México, y su necesidad básica de trasladarse por la ciudad. Sin embargo, esta movilidad cotidiana no se limita a desplazamientos origen destino, (de casa al trabajo, al supermercado, a la escuela, y de regreso), sino que conforma experiencias relacionadas con las largas distancias por recorrer, y sus consecuencias. Por ejemplo, se relaciona con el uso de diferentes medios de transporte, públicos y privados; con las pausas y tiempos de espera; con consumos en tiempo y dinero; con la evaluación subjetiva de las condiciones en que se traslada y con estancias temporales en diferentes lugares; entre otros aspectos que moldean los modos de habitar. Así, el análisis de la movilidad cotidiana trasciende el estudio de las redes y modalidades del transporte (Cerda y Marmolejo, 2010; Gutiérrez, 2010), incorporando la experiencia de los habitantes que viven y transitan la metrópoli en y desde las periferias, en su búsqueda por acceder no solo a ciertos equipamientos y servicios, sino también, a actividades, a personas, a relaciones, a lugares, a prácticas, entre otros elementos que constituyen la complejidad de la movilidad (Jirón y Mansilla, 2013; Mansilla, 2018, p. 25)

Así que, analizar el cómo llegar, en que llegar, con quien llegar, como regresar, desde donde y hasta donde. Aunado a la duración de los recorridos; el itinerario, los tiempos de espera, y todo lo que ocurre durante la práctica cotidiana de moverse en la metrópoli es importante para poder entender la forma en que estas se habitan y deberían planificarse (Jarvis, Pratt, Cheng-Chong Wu, 2001).

${ }^{3}$ La "repetición de situaciones" es un elemento común en los diferentes significados de experiencia (Abbagnano, 1993, p. 495). 


\section{ESTRATEGIAS Y PRÁCTICAS DE INVESTIGACIÓN PARA EL ESTUDIO DE LA MOVILIDAD COTIDIANA}

Para ilustrar la complejidad de la movilidad cotidiana se realizó trabajo de campo en el fraccionamiento Villas del Pedregal $^{4}$ ubicado en la periferia metropolitana de Morelia (Figura 1). La investigación contempló distintas estrategias de producción de datos como recorridos de observación, entrevistas semiestructuradas a los habitantes del fraccionamiento $\mathrm{y}$ observación participante ${ }^{5}$.



Figura 1. Ubicación del Fraccionamiento Villas del Pedregal (color morado) en la zona metropolitana de Morelia a $15 \mathrm{~km}$ de distancia del anillo periférico de la ciudad de Morelia, Michoacán. Fuente: elaboración propia sobre la base de Google Earth pro.

El principio metodológico de la investigación se basa en las narrativas de los habitantes, las cuales se entrecruzaron analíticamente con los recorridos de observación y con la observación participante. Las narrativas constituyen una ventana para aproximarse a los significados que los sujetos le otorgan a los lugares por los

\footnotetext{
${ }^{4}$ Villas del Pedregal inició su construcción en el 2006 y es considerado uno de los fraccionamientos mas grandes de México. Actualmente cuenta con 20000 viviendas en una superficie de 100,000 m2. (Espinosa, Vieyra y Garibay, 2015) con una poblacion aproximada de 50000 personas, con serios deficits en equipamientos y servicios $\mathrm{y}$ graves problemas de
}

que transitan y un medio para comprender la realidad de quienes narran.

Se narra lo que pasa, y justamente, por pasar
no queda; $\{\ldots\}$ en efecto, la narración es algo
insustituible en el conocimiento de las cosas
que pasan; salvo que imaginemos que todo lo
que pasa se pueda subsumir sin residuos bajo
una misma fórmula abstracta y general; que

inseguridad y violencia (La voz de Michoacán, 2018, 2019; MiMorelia.com, 2018; Noventa Grados, 2018).

${ }^{5}$ Se realizaron de manera intercalada 12 recorridos de observación y 12 entrevistas semiestructuradas, además de realizar durante 2 meses y medio la observación participante. 
todo sea susceptible de ser explicado en una ecuación lineal, sin desniveles de tiempo (Giannini, 1987, pp. 86 -87).

Las narraciones coadyuvan a entrever los significados que se crean y se recrean en la interacción de los actores con el espacio y también la valoración de su experiencia de movilidad se modela en esa interacción. No se puede entender la movilidad cotidiana, sin la comprensión social de lo que el habitante hace y siente cuando se desplaza, sin conocer sus motivos para desplazarse, los recursos con que se cuenta para hacerlo y el sentido que le da a sus acciones (Garfinkel, 2006).

Los habitantes pueden sentir que su vivienda es insatisfactoria porque está muy alejada de su trabajo o que su trabajo lo es, porque conlleva una travesía llegar hasta este. Puede sentir que su experiencia de movilidad es agradable porque se traslada rápidamente en un cómodo transporte público, o desagradable porque dura mucho tiempo en llegar a su destino, y/o porque el autobús en el que se traslada está lleno de pasajeros y no

\subsection{Caminando y observando el entorno habitacional}

Los recorridos de observación consisten en atravesar diferentes sectores del fraccionamiento caminando atento a lo largo de un trayecto, para establecer una relación vivencial con el fraccionamiento mediante una mirada desde adentro, desde el punto de vista del habitante del lugar (Hiernaux y Lindón, 2004a). El observar los lugares cotidianos-aquellos que el sujeto reconoce cuando los experimenta, y en donde establece una relación temporal y de significado al frecuentarlos- (Lorimer, 2011, pp. 21-23) permitió reconocer las condiciones del tiene lugar en donde sentarse y/o es muy incómodo. El habitante de la periferia puede pensar que su fraccionamiento no tiene el equipamiento necesario porque tienen que salir de éste para hacer sus compras; pueden sentir que sus ingresos son insuficientes porque gran porcentaje de estos lo gastan en transporte.

Por ello, los habitantes pueden experimentar variedad de situaciones favorables y/o desfavorables y pensar muchas cosas acerca de su movilidad, y si no se conocen las razones del porque piensan y sienten así, no es posible tener los elementos para comprender los motivos de la valoración su experiencia de movilidad de una forma $u$ otra. Los habitantes aprenden cuáles son los impedimentos y demás limitaciones de los espacios que transitan en relación con los acontecimientos sucedidos y las experiencias vividas en los mismos, y en esta medida aprenden a vivir en esos lugares $\mathrm{y}$, a la vez, vivirlos con sus condiciones favorables $\mathrm{y}$ desfavorables (Tuan, 2007, pp. 92-95).

fraccionamiento. Así, se pudo analizar el uso de los espacios públicos y las prácticas cotidianas que se desarrollan en estos y a partir de estos, así como la localización de los distintos equipamientos del fraccionamiento y su afluencia, los espacios degradados o abandonados, los caminos, las brechas, los atajos, los peatones, la ubicación de las paradas del transporte, así como las diferentes opciones y modalidades de este, todo a partir de la relación dialéctica entre las prácticas de los habitantes y las condiciones del territorio (Brikman, 2019). De esta manera. los recorridos de observación permitieron identificar, por un lado, condicionantes, 
limitantes, y obstáculos, y por otro las posibilidades, esfuerzos, facilidades y opciones para la movilidad de los habitantes desde el entorno habitacional.

\subsection{Entrevistar $y$ vislumbrar las narrativas}

Con base en las observaciones de los recorridos se definieron las preguntas y el enfoque del cuestionario para las entrevistas. Se definió realizar entrevistas semiestructuradas (Álvarez-Gayou, 2010, p. 111), ya que no tienen estructura estática, sino más bien flexible, lo que permite interactuar con el entrevistado y obtener no solo información puntual sino también de contexto (Mason, 2002, pp. 62-63). Así, el entrevistado narra las experiencias en las que es protagonista, ordena los sucesos, las prácticas $\mathrm{y}$ acciones en las que ha participado para que fluyan en la estructura de la narrativa personal, y además le da sentido en la vinculación con sus relaciones sociales (Kohler, 1993). Es decir, con las narrativas de experiencias conocidas sobre eventos, sucesos y situaciones vividas por sus vecinos, amigos, familiares, etc. (Flick, 2004, p. 8).

Por medio de las narrativas se da sentido e interpretación a las experiencias de movilidad cotidiana, a partir de las articulaciones entre las dimensiones espaciales micro y macro, además de las experiencias directas e indirectas de los habitantes (Bertaux, 2011). Las narrativas resultado de las entrevistas son eficaces herramientas para el análisis de las practicas espaciales, incluso De Certeau (2000, p. 128) las califica como parte inherente de las

\footnotetext{
${ }^{6}$ Los nombres de los entrevistados son seudónimos,
} con el fin de no revelar su identidad. mismas. Sin embargo, cabe señalar que es oportuno entrelazar las narrativas con otras herramientas propias del trabajo de campo, como los ya mencionados recorridos de observación, y la observación participante que a continuación señalaremos, ya que en su conjunto nos permiten interactuar con los sujetos en el marco del entorno habitacional con situaciones menos rígidas que las que generalmente caracterizan a las entrevistas a la puerta de la casa del entrevistado (Giglia, 2012, pp. 70-72).

\subsection{La técnica etnográfica de observación participante}

Con esta aproximación etnográfica se aprendió de la gente y de los significados que les atribuyen a sus prácticas (Spradley, 1980, p. 3). Así, sin protagonismo, en una actitud natural de inmersión, se ocupó el lugar de cualquier vecino (Mairal, 2000, pp.185-187), y se experimentó personalmente la movilidad cotidiana. Además, se hicieron múltiples recorridos a pie, en transporte público y en automóvil, sobre todo aquellos que los entrevistados enfatizaron que formaban parte de su vida cotidiana. Por ejemplo, la experiencia de movilidad de Martha, ${ }^{6}$ quien desde el fraccionamiento Villas del Pedregal recorría en su automóvil, largas distancias para llevar diariamente a su hijo a una escuela, ubicada cerca de la vivienda de sus padres, en donde ella había vivido hasta su adolescencia.

El conocer las experiencias de los vecinos no solo permitió reconocer lo que es característico del fraccionamiento, sino también los factores contextuales de la 
movilidad que sobrepasan las fronteras físicas de ese entorno habitacional. Así, dimos cuenta de los pormenores del uso del trasporte público; dónde se aborda, y a que partes de la ciudad llega; cuánto cuesta, y cuántas veces es necesario transbordar; cuales son los horarios en que está más saturado, y a qué horas termina el servicio; quienes lo utilizan mayoritariamente, y en donde bajan la mayoría de los pasajeros; cuales son las diferentes opciones de transporte público que existen y como se percibe el servicio. También dimos cuenta de cómo se experimenta, por un lado, la movilidad en automóvil particular, con el tráfico intenso y las grandes distancias que hay que recorrer, y por otro, la experiencia de caminar, tomar atajos, brechas y demás caminos que los habitantes transitan. Las prácticas cotidianas en el espacio son susceptibles de ser estudiadas mediante un trabajo de campo dinámico y relacional (Clifford, 1999, pp. 9091) que integre los sentidos y significados que los habitantes le otorgan a las prácticas que realizan en diferentes lugares y tiempos.

El uso de la entrevista en correlación con los recorridos de observación y la observación participante en el contexto de la investigación tuvo, por tanto, una triple finalidad. Primero, permitió recoger información cualitativa para entender los motivos de la movilidad, es decir las necesidades y deseos que el habitante busca satisfacer y cumplir, y por las cuales debe desplazarse. Por otro lado, permitió conocer los recursos con los que cuentan los habitantes para desplazarse, es decir, las diferentes modalidades de transporte que utilizan, así como sus gastos en tiempo y dinero, entre otros factores que influyen en la conformación de sus estrategias de movilidad. Por último, permitió comprender los diferentes sentidos del desplazamiento de los habitantes en sus dinámicas cotidianas, y con ello entender cómo conciben y dotan de significado a su experiencia de movilidad cotidiana en y desde la periferia metropolitana.

\section{HABITAR YENDO Y VINIENDO DESDE CASA}

Hay muchas movilidades tanto como formas de experimentarla; si la movilidad se basa en ausencia temporal del lugar de residencia (Stock, 2006, p. 7), las diferencias entre las movilidades radican en los motivos para ausentarse, es decir en el porqué de los desplazamientos. Son de considerar también en esta diferenciación de movilidades, los recursos con los que los habitantes cuentan para movilizarse. Por ejemplo, si realizan el recorrido en automóvil particular, transporte público o caminando, y en cómo alternan el uso de los diferentes medios de transporte en el tiempo y el espacio (Tabla 1). 
Tabla 1. Clasificación de los entrevistados en 4 grupos

\begin{tabular}{|c|c|c|c|c|}
\hline GRUPOS & RECURSOS PARA MOVILIZARSE & NOMBRE & EDAD & PROFESIÓN \\
\hline \multirow[t]{2}{*}{1} & \multirow{2}{*}{ Caminar - automóvil (ocasional) } & Alicia & 24 & Ama de casa \\
\hline & & Roció & 28 & Comerciante \\
\hline \multirow[t]{4}{*}{2} & \multirow{4}{*}{ Caminar - transporte publico } & Yadira & 27 & Ama de casa \\
\hline & & Guadalupe & 29 & Empleada \\
\hline & & José & 33 & Chofer \\
\hline & & Karla & 30 & Secretaria \\
\hline \multirow[t]{4}{*}{3} & \multirow{4}{*}{$\begin{array}{c}\text { Automóvil - } \\
\text { Transporte público (ocasional) }\end{array}$} & Martha & 31 & Empleada \\
\hline & & María & 27 & Ama de casa \\
\hline & & Jorge & 36 & Profesor \\
\hline & & Ruth & 34 & Cocinera \\
\hline \multirow[t]{2}{*}{4} & \multirow{2}{*}{ Motocicleta - automóvil } & Iván & 32 & Empleado \\
\hline & & Luis & 29 & Comerciante \\
\hline
\end{tabular}

Fuente: Elaboración propia. Se han clasificado a los 12 entrevistados en 4 grupos, con base en los recursos con que cuentan para movilizarse. Los nombres subrayados en gris son los 4 entrevistados que se han seleccionado para ejemplicar las movilidades cotidianas identificadas en la presente investigacion.

Otra diferencia en las movilidades radica en los sentidos ligados a quienes experimentan desplazarse (un individuo o un colectivo, una mujer o un hombre, una joven o una anciana, un niño solo o acompañado, una familia, etc.) con los obstáculos que hay que eludir a diario (Jirón e Imilian, 2018) y las ventajas que hay que aprovechar dadas las condiciones del recorrido, de quien se desplaza, y del medio en que se transporta. De esta manera, el habitante plantea desde su vivienda y entorno habitacional sus estrategias de movilidad, porque es ahí donde se da cuenta de sus necesidades y deseos de movilizarte, ahí inicia la movilidad, ahí se concreta y vuelve a iniciar, y es también donde se valora en términos de anclaje con el lugar, y donde tiene una impronta significativa (Hiernaux y Lindón, 2004b).

A pesar de que desplazarse entre lugares forma parte inherente de la vida urbana contemporánea, muchas de las investigaciones que desde las ciencias sociales han abordado la movilidad, lo han hecho de manera estática (Urry, 2003), en particular en América Latina (Jirón e Imilian, 2018). Es decir, la movilidad se concibe solamente como el trazo de un recorrido entre dos o más lugares, sin la integración del movimiento constante, de las pausas, las transiciones, los periodos de inmovilidad, los obstáculos que hay que salvar, los cambios de ruta y las estancias temporales en diferentes lugares.

Las aproximaciones al estudio de la ciudad que históricamente se han cultivado en las Ciencias Sociales, han sido en términos de lugar ocupado (Delgado, 1999, pp. 37-39), lo que pareciera llevar implícito que quienes habitan la ciudad no tienen necesidades $\mathrm{y}$ deseos de desplazarse cotidianamente hacia diferentes lugares sino solamente de ocupar un lugar. Por su parte David Ley (Lindón, 2008 cita a Ley, 1983), denomina Geografías del Homo Dormiens, a aquellos análisis estáticos que abordan a la ciudad como si los 
habitantes de determinadas zonas fueran sujetos dormidos que permanecen todo el día sin moverse en su vivienda, realizando de manera constante las mismas actividades.

En ambos análisis se homogenizan las zonas de la ciudad por los usos del suelo, el nivel socioeconómico de sus habitantes, o por las prácticas urbanas; como si todos los habitantes fueran iguales, con las mismas ocupaciones, aspiraciones y expectativas, o que en las diferentes zonas de la ciudad no existiera diversidad. También en estos análisis se privilegia la materialidad y se hace a un lado al sujeto y sus prácticas cotidianas, esto por estar regulados por presupuestos de objetividad, en los que se asume que la ciudad está separada del sujeto y es un objeto independiente de los habitantes.

Los habitantes construyen el espacio permanentemente al recorrerlo (Massey, 2006), es decir, que el espacio se construye en movimiento (Ingold, 2008). En este contexto, Delgado (1999) propone estudiar la ciudad tomando en cuenta la relación móvil de los habitantes en sus prácticas cotidianas. Una mirada a la movilidad desde este enfoque implica la consideración de todo lo que los habitantes hacen y sienten en sus desplazamientos por diferentes lugares de la ciudad. Para ello, es necesario también tener en cuenta la duración de los desplazamientos, los diferentes medios de transporte utilizados, el itinerario seguido y todo esto, en su reiteración en el tiempo, es decir a través de los días, las semanas, los meses, etc. (Lindón, 2006, pp. 374-375).

Si bien existe una marcada dependencia de los habitantes tanto en el contexto mundial (Ascher, 2004; Kruger, 2018, pp. 179-185; Robert, 2018, pp. 41-48), como en el de México (Duhau y Giglia, 2008, pp. 204-205), al uso de los transportes públicos y privados para desplazarse por la metrópoli; la movilidad cotidiana también se experimenta caminando. Un ejemplo es la experiencia de Alicia, una ama de casa que recientemente se convirtió en madre, comentó que no necesita automóvil y puede hacer sus compras caminando. Explicó que su marido le había dado unas lecciones de conducir en las calles menos transitadas a las orillas del fraccionamiento, pero por miedo nunca aprendió; puesto que, el automóvil familiar era un taxi, el instrumento de trabajo de su marido y la principal fuente de ingreso familiar. Por ello, ella había decidido desplazarse caminando y únicamente los fines de semana cuenta con su marido para trasladarla en automóvil.

- ¿En dónde compran lo básico?

- Pues voy aquí al "Regalo de Dios" (supermercado regional), porque está más barato y los fines de semana surtimos allá en "Soriana" (cadena mexicana de supermercados).

- ¿En cuál Soriana?

- El de plaza Morelia, para aprovechar y dar la vuelta. Como hay cine, comida y muchas cosas (Figura 2). 


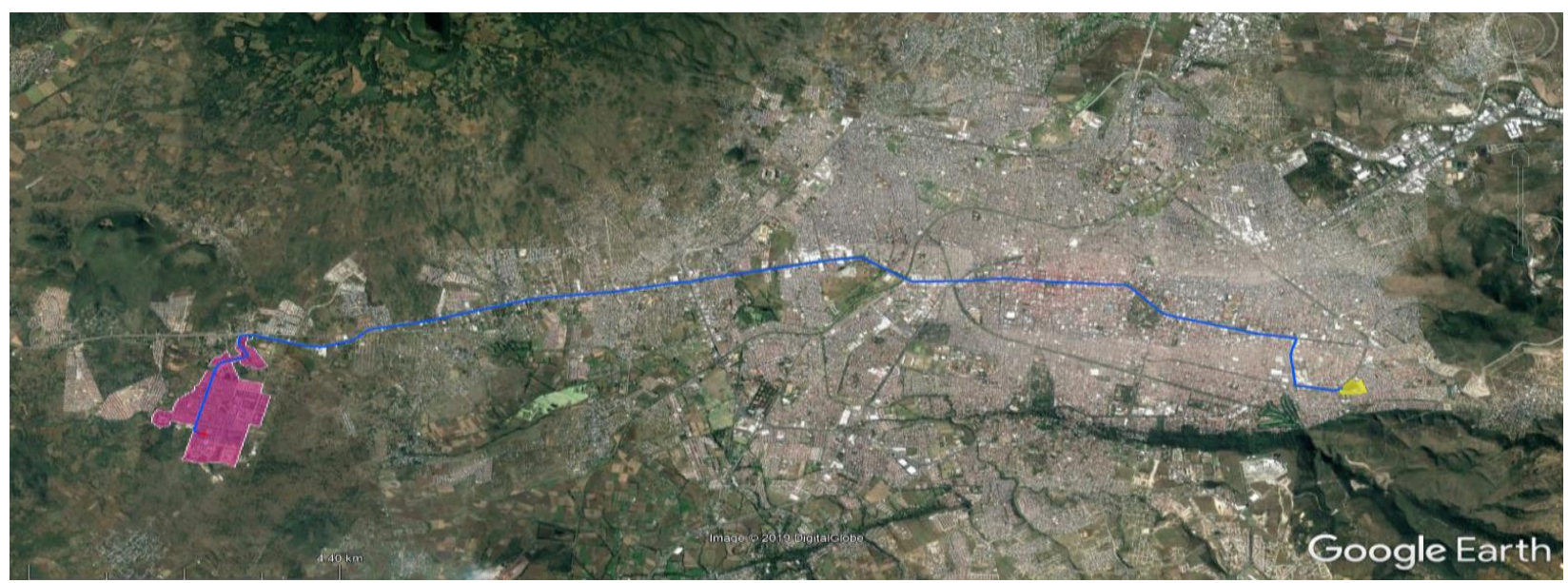

Figura 2. Con línea azul se señala el desplazamiento en automóvil que Alicia y su familia indicaron realizar los fines de semana para el abasto y el ocio, desde su casa en Villas del Pedregal (color morado) a la plaza Morelia (color amarillo). El desplazamiento en automóvil entre estos dos lugares cubre una distancia de ida y vuelta de $48 \mathrm{~km}$ con una duración 90 minutos aproximadamente. Fuente: elaboración propia sobre la base de Google Earth pro.

- Oye; ¿Y el "Regalo de Dios" dónde está? ¿Está cerca?

- Pues sí.

- ¿Qué tanto? ¿Cómo llegas?

- Pues esta como a uno o dos kilómetros, más o menos. No tan lejos, me voy caminando. El problema es que no hay banqueta ni nada.

- ¿Cómo? ¿Por qué?

- Es que está al borde de carretera, antes la entrada al fraccionamiento se ve cuando viene para el fraccionamiento. Le digo no tan lejos, pero imagínese ahí con la carriola, si me iba con cuidado nomas volteando a ver a los coches que venían. La verdad si da miedo de que lo atropellen a uno con todo y niño.

- Oye y cuanto tardas en ir y venir?

- Pues como 45 minutos en ir y otros 45 en regresar.

- Pues no están tan cerca.

- Pues no, pero ya le corto camino, por la brecha. Mucha gente se va por ahí y si te ahorras unos 10 o 15 minutos.

- ¿Pero por ahí, como le haces? ¿Te llevas la carriola también?

No por ahí no me la llevo, ahí lo llevo cargando, ósea si hay caminos, pero es de tierra, así que mejor prefiero cargar al niño.

- ¿Hay varios caminos?

-Yo he visto dos, pero prefiero uno que me deja ya casi llegando a la tienda, en el otro camino todavía te saca sobre la carretera y tienes que caminar unos metros.

- ¿Y dónde está la brecha? ¿Desde de aquí de tu casa por donde te vas?

- Pues yo me voy por cualquier calle, pero para explicarle más fácil, se va por esta calle, la de la casa, que se llama calle 8 , hasta la penúltima calle, que es la calle 3, pero también se puede ir hasta la última. Yo prefiero irme por la penúltima porque en la última está muy sola. Bueno, luego da vuelta a su izquierda y recorre toda esa calle con rumbo hacia el acceso del fraccionamiento y de ahí a su derecha va a ver las dos brechas que le digo, la segunda que inicia en la prolongación de esa calle es la que lo dejar más cerca del super (Alicia).

Sin embargo, la estrategia de movilidad adoptada por Alicia no deja de tener sus riesgos, ya que el trasladarse caminando por las estrechas veredas en el terreno baldío, le parece muy desagradable y le da mucho miedo porque ha visto tirados condones, toallas femeninas, ropa interior, pañales, entre otras cosas.

- ¡De verdad! ¿Todo eso has visto? Y entonces, ¿por ahí, se te hace el recorrido más seguro? 
- Pues sí da mucho miedo ese recorrido, pero bueno ahí no te pueden atropellar. Aunque me puede salir alguien o algo y ahí ni quien me ayude. Pero bueno hasta ahora no nos ha pasado nada.
-Y cada cuando vas a ese super?

- Pues como cada tercer día, aunque a veces más seguido (Alicia), (Figura 3).

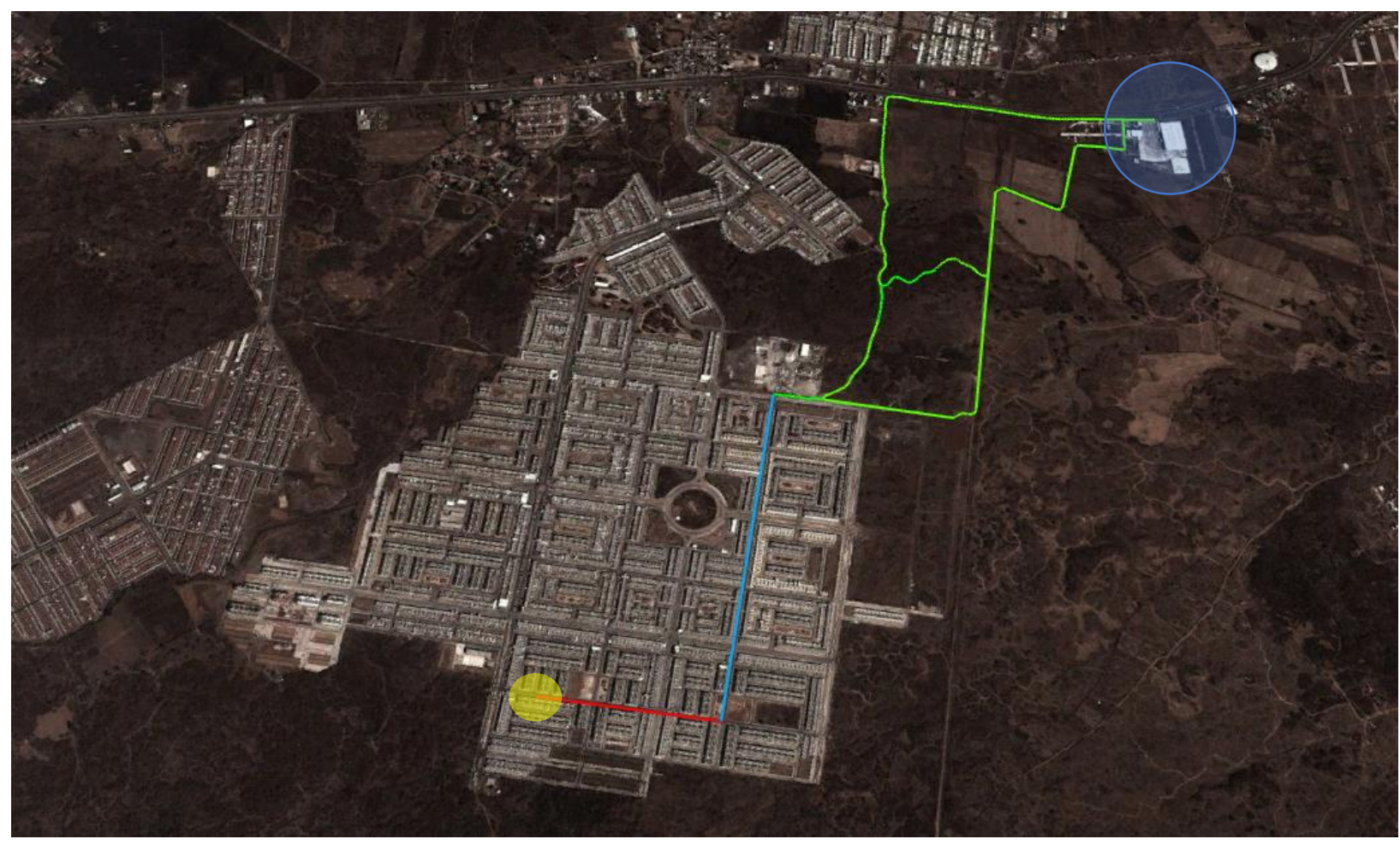

Figura 3. El desplazamiento de Alicia hacia el super inicia en su casa (círculo amarillo) a lo largo de la línea roja (calle 8), después por línea azul la (calle 3) y finalmente por las líneas verdes (brechas en el terreno sin urbanizar) hasta el super de nombre "Regalo de Dios" (circulo azul). La distancia recorrida de ida y vuelta es de 6 kilómetros y medio aproximadamente. Fuente: elaboración propia sobre la base de Google Earth pro.

El estudio de las prácticas de caminar resulta insuficiente si no se toma en consideración las dimensiones de las corporalidades y las practicas sensibles de las personas (Tironi, 2018, p. 17). Por lo tanto, el cumplimiento de normas y estándares en la construcción y diseño de espacios, si bien son necesarios, no son suficientes para promover el caminar y la apropiación del espacio

7 El Fraccionamiento Villas del Pedregal fue galardonado en el Estado de Michoacán con el Premio Estatal de la Vivienda 2011 y en el país con tercer lugar nacional en el Premio Vida Integral Infonavit 2012, público; aunque los proyectos urbanos sean evaluados y premiados $^{7}$ por incluir en su diseño infraestructuras para caminar serán los habitantes quienes al habitar en esos espacios tengan los elementos suficientes para valorarlos y usarlos (Espinosa, 2015). En definitiva, la calidad en el diseño del proyecto urbano y arquitectónico incide en la práctica del caminar, sin embargo, el evaluar

(dicho premio recompensa a los desarrollos mejor equipados del país, que brindan óptima interacción de la comunidad con el entorno). 
únicamente las condiciones físicas de las infraestructuras para ver si es posible desplazarse sobre esta es cuestionable.

La experiencia de la movilidad es moldeada en el tiempo por el entorno social, y en esta interacción puede restringirse, disminuirse o anularse por el temor de los habitantes no solo a usar el espacio público, sino incluso a salir de su vivienda. La primera reacción de las personas ante ese peligro es el miedo, y con ello el impulso a protegerse y refugiarse en su vivienda (Davis, 2001). Como el caso de Yadira, quien por no conocer a sus vecinos y ante la percepción del ambiente de inseguridad en el entorno, prefiere salir lo menos de su casa y que sus hijos jueguen ahí dentro.

- ¿Oye y por las tardes ya que los niños salieron de la escuela, como se entretienen, en donde juegan?

- Los niños juegan aquí en la casa; ahí muy de vez en cuando iban a los juegos infantiles, pero yo los acompañaba para estarlos cuidando y aprovechaba para caminar un poco por ahí.

- ¿Están peligrosos?

- Pues como no conozco más que a mis vecinos de los lados, no vaya a ser. Y luego dicen que se mete gente de otros lados aquí para hacer maldades; por eso prefiero que jueguen aquí en la casa. Además, los juegos, ya están muy descuidados.

- Pero ¿Hay más juegos no? ¿No se va a otros? - Si hay más, pero pues estos son los según nos corresponden a los de la zona.

- Pero ¿Le dicen algo si se van a otros juegos?

- No, no te dicen nada, pero como los vecinos están en todo menos en misa ${ }^{8}$, la verdad no está muy cómoda esa situación. Aunque yo lo entiendo porque luego se mete gente de otra zona del fraccionamiento.

- ¿Usted los ha visto?

\footnotetext{
${ }^{8}$ Dicho popular que se refiere a que los vecinos prestan
} atención a situaciones que no les deberían de importar.
- Si, pues a unos adolescentes, andan rondando por ahí, han de ser pandilleros, yo creo, y pues si da miedo que algo le hagan a los niños o a mí también. Por eso cuando si salimos procuramos que sea temprano en la mañana, ya en la tarde mejor no salir (Yadira).

Así, el uso del espacio público y la práctica de movilizarse caminando deben de comprenderse como recursos y capacidades de las habitantes desigualmente distribuidas, ya que depende de las condiciones materiales y de diseño del espacio, y también de la organización y sociabilidad de quienes usan, se desplazan y habitan los lugares. Para comprender la práctica de caminar es necesario generar estrategias metodológicas que en su interacción recojan las experiencias de los habitantes sobre su desplazamiento, involucrando además del cuerpo en su relación con el espacio, a los sentidos. Se debe comprender el caminar como instrumento de composición de la ciudad y medio de anclaje del habitante a esta, es el primer paso para impulsarlo como practica de movilidad sustentable (Thomas, 2007).

En este contexto, no basta con la construcción de infraestructuras que permitan el desplazamiento del punto A hacia el $\mathrm{B}$, hace falta poner al centro del análisis de la movilidad a quienes se desplazan, y tomar en cuenta las diferentes estrategias que adoptan para movilizarse en las diferentes escalas espaciales (Sheller, 2018).

Por otra parte, las estrategias de los habitantes para desplazarse por la ciudad se combinan, se complementan, y van variando en el tiempo conforme a la valoración de sus experiencias de movilidad. Por ejemplo, la 
narración de Iván sobre sus desplazamientos primero usando una motocicleta y después un automóvil, es elocuente al respecto.

- Y además del transporte público, ¿Que opciones tienes para desplazarte?

- Pues nada más en coche, no hay de otra, por ejemplo, una bici solo serviría para hacer ejercicio aquí dentro del fraccionamiento, para salir de aquí hasta Morelia en bici, no se puede, está muy lejos y es peligroso.

- ¿Y tienen coche?

- No, pero lo que hacemos, es que agarramos el coche de mi papá, o sea él nos lo presta.

- ¿Él vive aquí con ustedes?

- No, no vive aquí, vive cerca del centro. Pues cuando lo visitamos a veces aprovechamos para traernos el coche. No queremos abusar, en ocasiones no lo dejamos como una semana. Esto es en lo que ahorramos para comprarnos uno. Hace tiempo nos compramos una motoneta pensando en que era una buena opción porque no gasta tanta gasolina, pero la verdad es que esta peligroso usarla.

- ¿Por qué lo dices?

- Ah, lo digo por la carretera, como agarras carreta para llegar aquí, pues esta peligroso y ha habido accidentes.

- ¿En dónde ha habido accidentes?

- Pues aquí adentro, pero también afuera, sobre todo en el acceso, a la hora de entrar, esta peligroso.

- Mire las noticias, ya ha habido varios accidentes, adentro y afuera. Hubo un accidente de taxi en la entrada que estuvo muy feo, el coche quedo casi inservible. $\mathrm{Y}$ ya ha habido hasta muertos, supe de uno que manejaba una moto que se murió, ahí en la entrada; por eso ya hasta tenemos la de nosotros a la venta; y pues si le digo, por eso mejor pedimos el coche (Iván).

Iván también comentó que obtuvo crédito para comprar su motocicleta, dio un enganche y realizo pagos mensuales; por esta razón considera que debería dar uso a su motocicleta, pero a la vez le da miedo hacerlo, porque hay muchos accidentes en la zona donde se involucran motociclistas. Aunado esto su esposa Rosa está embarazada, situación que lo anima a pensar en su integridad física.

Ya vamos a ser papás, y le digo que los dos nos tenemos que cuidar. No solo yo, él también porque si le llega a pasar algo, me deja sola con el niño, ¡luego que hacemos!, Yo de mamá soltera, ¡imagínese! Por eso le digo que me da pena con su papá de dejarlo sin coche, pero pues, ya en un futuro nos compraremos uno, aunque sea "chafita" ${ }^{9}$, porque las motos si son peligrosas, también los coches, pero las motos más, de verdad que si ha habido aquí accidentes (Rosa).

Reconocer los múltiples motivos que inciden en las estrategias de movilidad de los habitantes implica dar razón de los recursos con los que estos cuentan para desplazarse. Como el caso de Iván y Rosa, quienes poseen una motocicleta que prefieren no usar y mejor pedir prestado un automóvil. Es ahí donde el análisis de las experiencias de movilidad adquiere significación, porque hace evidente el porqué de las decisiones de una familia por adoptar cierta estrategia de movilidad y hacer los ajustes necesarios en el tiempo. Como el caso de Martha, quien con el pasar del tiempo vio la necesidad de ajustar su estrategia de movilidad, ya que para ella era muy cansando desplazarse diariamente más de $60 \mathrm{~km}$ en un trayecto de más de dos horas manejando su automóvil, desde su casa, a la escuela de su hijo y finalmente a su trabajo, esto de ida $\mathrm{y}$ vuelta, como narra a continuación.

${ }^{9}$ Cualquier cosa que carece de calidad. 
- ¿Qué haces durante el día desde que te levantas? ¿A qué hora sales? ¿A dónde vas?

- Pues es complicado, porque cada semana es diferente.

- ¿Porque lo dices?

- Bueno, es que mi hijo no alcanzo lugar en la escuela que está aquí en el fraccionamiento, está muy saturada, y pues como no queríamos que perdiera el año, decidimos con mi esposo que lo íbamos a inscribir en la escuela en que yo iba de niña, una escuela que esta por la casa de mis papás.

- Y, ¿Por dónde está? ¿Es primaria?

- Si es primaria, está ahí en la Primo Tapia ${ }^{10}$, a la vuelta de la casa de mis papás.

- No pues, ¿Les queda lejos no?

- $\mathrm{Si}$, pero no queríamos que se quedara sin estudiar, así que decidimos que se fuera allá. A esa escuela yo fui de niña, y pues además ahí, mi mamá está cerca para recogerlo.

- Y, ¿Cómo lo llevas hasta allá?

- Pues en el coche, lo llevaba antes de irme a trabajar, pero si esta largo el trayecto. Como te dije, le pedía a mi mamá lo recogiera y ya pasaba yo en la noche saliendo del trabajo por él. Aunque la verdad, si duraba mucho y además me salía caro.

- ¿Cuánto tardas en llevarlo?

- Pues como una hora y media de ida y otra una y media de vuelta, claro dependiendo del tráfico.

- Es mucho, y ¿Cuánto dinero te gastas?

- Pues no se bien, varia, pero yo creo entre 400 y 500 pesos a la semana ${ }^{11}$. Por eso decidimos que se quedara allá mi hijo con mis papás; mi mamá nos dijo que ella se encargaba con gusto de llevarlo a la escuela y recogerlo, pues le queda muy cerca, como está ahí a la vuelta la escuela, para ella es fácil.

- Pero ¿Por qué dices que todas las semanas es diferente?
- Porque al principio se quedaba allá y solo veíamos al niño los fines de semana, y así estuvimos un tiempo, pero lo extrañábamos mucho la verdad, y cada que íbamos no nos queríamos venir acá a la casa, y pues el niño llore y llore, armaba escándalo, ya después nos dijo mi mamá que ya nos quedáramos allá.

- ¿Esta amplia la casa? ¿Si caben?

- Si, si cabemos, no está muy grande la casa, pero sí, porque tiene 4 habitaciones. La cosa es que no queríamos dejar esta casa, así que decidimos quedarnos una semana allá y otra acá, pues para no abandonar esta casa, porque nuestro trabajo nos costó sacarla, de hecho, todavía la estamos pagando.

- Entonces, ¿Viven aquí y allá?

- Pues sí, tenemos ropa allá y acá, también mi esposo tiene varias cosas allá. Y es que también mi trabajo está más cerca de aquella casa, y pues llego más rápido y gasto menos en gasolina (Martha).

Stock (2006) denomina "Hábitar Politópico", al habitar temporalmente en varias residencias sin tener alojamiento fijo, $y$ aunque lo aplica principalmente al análisis del turismo, la experiencia de Martha muestra que este modo de habitar forma parte de la experiencia de movilidad de los habitantes de la periferia metropolitana, quienes con sus prácticas cotidianas electivas, elegidas y asumidas, habitan en diferentes tiempos y en diferentes viviendas (Figura 4).

\footnotetext{
${ }^{10}$ Primo Tapia es el nombre de la zona habitacional.
}

${ }^{11}$ Alrededor de 20 - 25 dolares estadounidenses. 


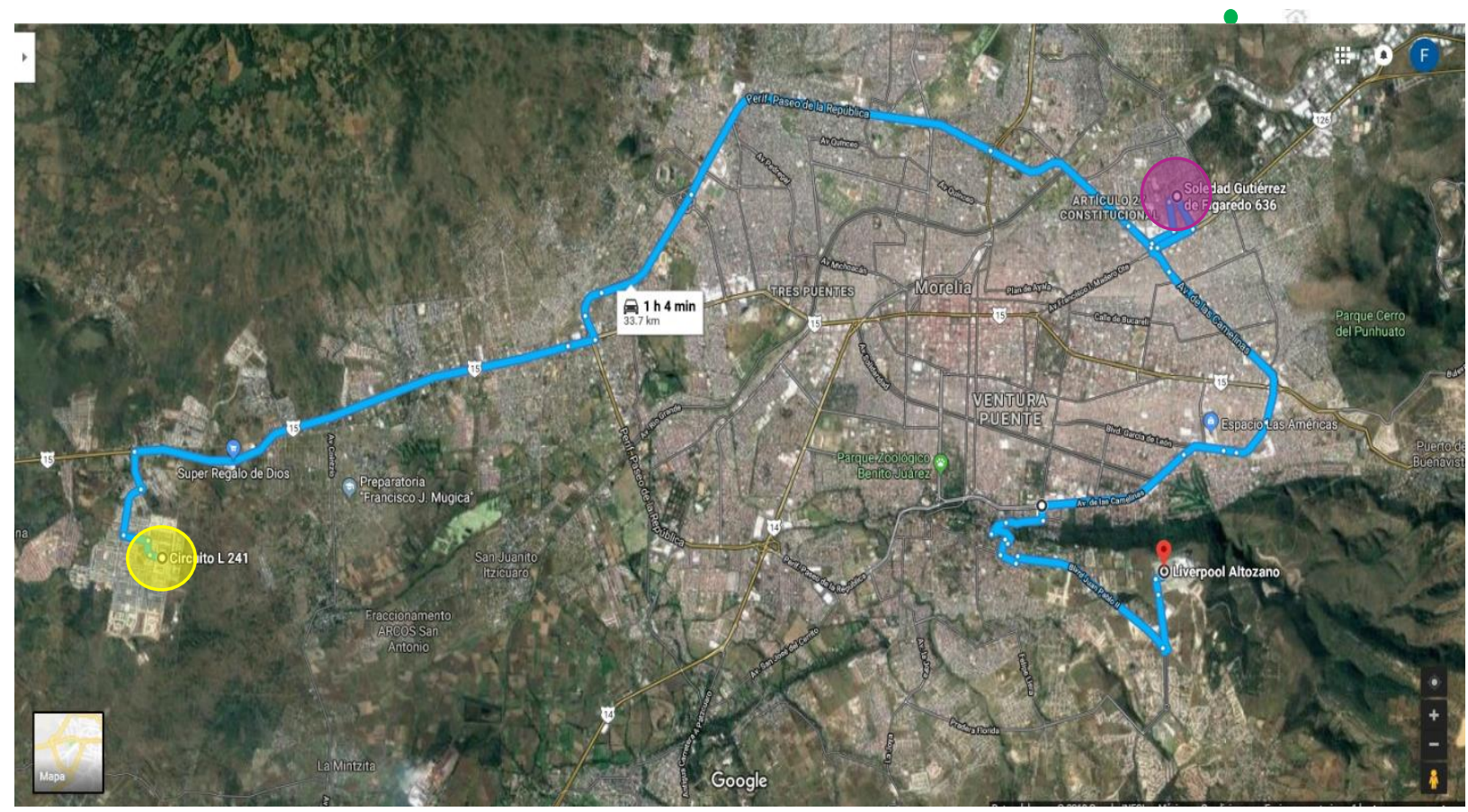

Figura 4. Modo de habitar politópico de Martha y su familia. Con circulo amarillo zona del fraccionamiento Villas del Pedregal en donde se encuentra su vivienda, con morado la zona de Primo Tapia en donde se encuentra la casa de su mamá y con círculo rojo se señala la ubicación del centro comercial de nombre Altozano, en donde Martha trabaja. El desplazamiento en automóvil entre estos tres lugares cubre una distancia tan solo de ida de $33.7 \mathrm{~km} \mathrm{y} 70$ minutos aproximadamente. Fuente: elaboración propia sobre la base de Google Earth.

El habitar politópico se caracteriza por la constante búsqueda de ajuste entre lugares y prácticas, con relación a distancias por recorrer, tiempos de duración y costos para ello (Lazzarotti, 2006, p. 86). Los habitantes tienden a elegir los lugares apropiados para desempeñar sus prácticas, mediante la adopción de estrategias de desplazamiento muy diversas, por diferentes medios y para diferentes fines. Así que muchos habitantes de hoy en día se encuentran involucrados con múltiples lugares, y en su movimiento constante se asumen como multiresidentes e individuos móviles (Stock, 2001).

Las experiencias de movilidad se conforman de rutinas de desplazamientos por diferentes medios de transporte y hacia diferentes zonas de la ciudad, con estancias en diferentes lugares y tiempos. En este contexto, el habitar la metrópolis de hoy en día, con sus dinámicas y escalas, implican superar el espacio de la vivienda e integrar en el análisis el sistema de escalas espaciales que se relacionan entre sí, en las que están incluidos además el conjunto habitacional, los espacios públicos, el entorno urbano, y la metrópoli en su conjunto. Este sistema de escalas espaciales se relaciona entre sí mediante oportunidades, obstáculos a través del espacio-tiempo que se expresan en las prácticas de movilidad cotidiana (Jirón y Mansilla, 2013).

De esta manera la experiencia de la movilidad es diversa, desigual, e inequitativa para los habitantes; conforme a que actúan "no sobre, sino con" el espacio (Lussault, 2015, pp. 172-173) en sus diferentes escalas y los recursos con los que cuentan para 
movilizarse en la metrópoli. Como se evidencia en el caso de Martha y su familia que habitan en dos residencias muy alejadas entre sí. El caso de Yadira, quien usa poco el espacio público por temor a la inseguridad y procura que sus hijos jueguen en casa para no exponerlos. El caso de Alicia quien se desplaza caminando desde su casa al supermercado más cercano acortando su recorrido por brechas en terrenos baldíos que considera peligrosos y no aptos para caminar, o el caso de Iván y Rosa quienes ajustan sus estrategias de movilidad desplazándose en diferentes medios de transporte, en diferentes tiempos y de acuerdo con sus posibilidades.

En la perspectiva del actuar con el espacio se inhiben prácticas, pero también se impulsan, e incluso otras más se adaptan a los motivos, recursos y sentidos de los habitantes y las condiciones del espacio. El estudiar los vínculos entre las prácticas de los habitantes $\mathrm{y}$ el espacio en sus diferentes condiciones, dimensiones y escalas es clave para comprender la producción de la metrópoli de la actualidad; una metrópoli en movimiento, en la que la movilidad de los habitantes se concibe más allá del conjunto de los desplazamientos que realizan en el espacio, en las experiencias con el espacio.

\section{CONCLUSIONES}

La vivienda alberga un conjunto de connotaciones y experiencias que su habitar le confiere, es ahí donde se enmarca el proyecto cotidiano de las personas para ganarse la vida (Giannini, 1987, p. 33). Es ahí también donde la experiencia de movilidad cotidiana está circunscrita, porque para ganarse la vida el habitante se moviliza entre lugares, hace pausas mas no deja de moverse, habita en movimiento (Ingold, 2008; Massey, 2006). De esta manera el habitar no es estático y ha superado la concepción del lugar como un punto en el espacio (Ingold $\mathrm{y}$ Vergunst, 2008). Como sugiere Massey (2006), en vez de pensar los lugares como áreas delimitadas, con fronteras definidas e inmóviles, se deberían imaginar como redes articuladas de relaciones sociales, experiencias y significados; como nodos abiertos y entramados de flujos con influencias e intercambios externos.

Este texto, incorpora al estudio de la movilidad cotidiana, diferentes dimensiones y practicas invisibles desde los análisis de la planificación urbana y de diseño de infraestructuras, pero que no por ello dejan de formar parte de los modos de habitar la metrópoli. Se buscó enfatizar la compleja y cambiante trama de recorridos de los habitantes que no se limitan al acceso a los lugares de trabajo, abasto, entretenimiento, etc., pues se incluye dimensiones dinámicas que se relacionan con los diferentes motivos, recursos y sentidos para desplazarse, en tiempos voluntarios y forzosos, con pausas breves y prolongadas en diferentes alojamientos.

Asimismo, se promueve no minimizar el caminar en relación con otras formas de movilidad consideradas de mayor trascendencia, como las que se practican en el automóvil o en el transporte público. Se enfatiza la importancia que tiene el caminar en la planificación de nuestras metrópolis. La práctica de caminar es generalmente menospreciada por su carácter ordinario, porque siempre se está caminando, aunque no se caiga en cuenta de ello; se camina hacia el coche, hacia la parada del autobús, se camina 
en la oficina y también en la propia casa, se camina todo el tiempo porque caminar es común, es mundano. En este sentido, y con miras a implementar mejores soluciones para planificar las metrópolis, se sostiene que explicar la movilidad cotidiana implica reconstruir los desplazamientos de los habitantes entre las diferentes escalas espaciales, desde los motivos para movilizarse, los recursos disponibles para hacerlo y los sentidos de gozar o de sufrir cada desplazamiento con sus obstáculos y estrategias para superarlos.

Por último, la aproximación experiencial a las movilidades cotidianas abre toda una perspectiva de estudio sobre el habitar la metrópoli. Se propone estudiar las experiencias de movilidad por medio de las narrativas de los habitantes, sin perder de vista la experiencia del investigador en el trabajo de campo; en esta correspondencia, las narrativas se conforman en conversaciones sobre las experiencias de movilidad y no solo con respuestas puntales a las preguntas de la entrevista. En este contexto, y siguiendo a Latour (2005) se considera conveniente respetar el lenguaje de los entrevistados con sus frases, dichos, refranes y todas las expresiones coloquiales que forman parte de sus narrativas, y que, aunque pueden parecer incorrectas en el entorno científico y académico, dicen mucho de la realidad que experimentan al desplazarse. Todo esto permite reconocer que las experiencias de movilidad no se limitan a funcionalidades y fronteras físicas en el espacio, sino que incorporan procesos de significación que no solo moldean los modos de habitar de los habitantes la metrópoli, sino que son parte de estos transformándose a sí mismos.

\section{REFERENCIAS BIBLIOGRÁFICAS}

Abbagnano, N. (1993). Diccionario de Filosofía. México: Fondo de Cultura Económica.

Álvarez-Gayou, J. L. (2010). Cómo hacer investigación cualitativa:

Fundamentos y metodología. México: Paidós.

Ascher, F. (2004). Los Nuevos principios del urbanismo. Madrid: Alianza.

Bertaux, D. (2011). El enfoque biográfico: su validez metodológica, sus potencialidades. Acta Sociológica, 56, 61-93. doi: 10.22201/fcpys.24484938e.2011.56.29 458.

Brikman, D. (2019). El lente de la movilidad. Un análisis de Villa 15, sus características de segregación y las prácticas cotidianas de sus habitantes. Revista Transporte y Territorio, 20, 387-423.

doi: 10.34096\%2Frtt.i20.6398.

Cerda, J., y Marmolejo, C. (2010). De la accesibilidad a la funcionalidad del territorio: una nueva dimensión para entender la estructura urbanoresidencial de las áreas metropolitanas de Santiago (Chile) y Barcelona (España). Revista de Geografía Norte Grande, 46, 5-27.

Clifford, J. (1999). Itinerarios transculturales. Barcelona, España: Gedisa. doi: 10.4067/S071834022010000200001 . 
Cresswell, T. (2006). On the Move. Mobility in the Modern Western World. New York, USA: Routledge.

Cresswell T. (2010). Towards a politics of mobility. Environment and Planning D: Society and Space, 28(1), 17-31.

Davis, M. (2001). Beyond Blade Runner: Urban Control/The Ecology of Fear. Westfield, N.J.: Open Magazine/Pamphlet Series.

De Certeau, M. (2000). La invención de lo cotidiano. 1. Artes de hacer. México: Universidad Iberoamericana, ITESO.

Delgado, M. (1999). El animal público: Hacia una antropología de los espacios públicos. Barcelona: Anagrama.

Duhau, E., y Giglia, A. (2008). Las reglas del desorden: habitar la metrópoli. México: Siglo XXI, UAMAzcapotzalco.

Espinosa Ortiz, F. (2015). Vivienda de interés social y calidad de vida en la periferia de la ciudad de Morelia, Michoacán. México: UNAM, PUEC, CIGA, Infonavit.

Espinosa Ortiz, F., Vieyra, A., y Garibay, C. (2015). Narrativas sobre el lugar. Habitar una vivienda de interés social en la periferia urbana. Revista INVI, 84(30), 59-83. Recuperado de http://revistainvi.uchile.cl/index.php/INVI /article/view/905.

Flick, U. (2004). A Companion to Qualitative Research. Londres: Sage Publications.

Garfinkel, H. (2006). Estudios en Etnometodología. Barcelona: Anthropos Editorial; México: UNAM; Bogotá: Universidad Nacional de Colombia.
Giannini, H. (1987). La reflexión cotidiana. Santiago de Chile: Editorial Universitaria.

Giglia, A. (2012). El habitar y la cultura: perspectivas teóricas y de investigación. Barcelona: Antrhropos; México: UAM - Iztapalapa.

Gutiérrez, A. (2010). Movilidad, transporte y acceso: una renovación aplicada al ordenamiento territorial. Scripta Nova. Revista Electrónica de Geografía y Ciencias Sociales, 331(86).

Recuperado de http://www.ub.es/geocrit/sn/sn331/sn-331-86.htm.

Hiernaux, D., y Lindón, A. (2004a). Repensar la periferia: De la voz a las visiones exo y egocéntricas. En A. G. Aguilar (Coord.), Procesos metropolitanos y grandes ciudades: Dinámicas recientes en México y otros países (pp. 413-443). México: UNAM, Instituto de Geografía, PUEC, CRIM, Miguel Ángel Porrúa.

Hiernaux, D., y Lindón, A. (2004b). Desterritorialización y reterritorialización metropolitana: la ciudad de México. Documents d'Analisi Geografica, (44), 71-88. Recuperado de https://ddd.uab.cat/pub/dag/02121573n 44/02121573n44p71.pdf

Ingold, T. (2008). Bindings against boundaries: Entanglements of life in an open world. Environment and Planning A, 40(8), 1796-1810. doi: 10.1068/a40156.

Ingold, T., y Vergunst, J. L. (2008). Ways of walking: ethnography and practice on foot. Hampshire - Burlington: Ashgate 
Jarvis, H., Pratt, A., y Cheng-Chong Wu, P. (2001). The secret life of cities: the social reproduction of everyday life. New York: Pearson Education.

Jirón, P., y Mansilla, P. (2013). Atravesando la espesura de la ciudad: Vida cotidiana y barreras de accesibilidad de los habitantes de la periferia urbana de Santiago de Chile. Revista de Geografía Norte Grande, 56, 53-74. Recuperado de http://repositorio.uchile.cl/handle/2250/1 30635.

Jirón, P., e Imilan, W. (2018) Moviendo los estudios urbanos. La movilidad como objeto de estudio o como enfoque para comprender la ciudad contemporánea. Quid, 16(10), 17-36. Recuperado de http://repositorio.uchile.cl/handle/2250/1 53116.

Kohler, R. C. (1993). Narrative Analysis. Newbury Park, CA: Sage.

Kruger, R. (2018). Transporte. En D. Zunino, G. Giucci y P. Jirón (Eds.), Términos clave para los estudios de movilidad en América Latina (pp. 179 -186). Buenos Aires: Editorial Biblos.

Latour, B. (2005). Reassembling the Social. An Introduction to Actor-Network Theory. Oxford University Press.

La voz de Michoacán. (21 de abril de 2018).

Escasez de agua, tormento de Villas del Pedregal. Recuperado de https://lavozdemichoacan.com.mx/morel ia/escasez-de-agua-tomento-de-villasdel-pedregal/.

La voz de Michoacán. (24 de febrero de 2019). Villas del Pedregal, una «ciudad» sin ley; persiste ola de robos y violencia. Recuperado de https://lavozdemichoacan.com.mx/morel ia/villas-del-pedregal-una-ciudad-sin-

ley-persiste-ola-de-robos-y-violencia/.

Lazzarotti, O. (2006). Habiter, aperçus d'une science géographique. Cahiers de géographie du Québec, 50(139), 85-102. doi: 10.7202/012936ar.

Lindón, A. (2006) Geografías de la vida cotidiana. En D. Hiernaux y A. Lindón (Dirs.), Tratado de Geografía Humana (pp. 356-400). Barcelona: Anthropos, México: UAM - Iztapalapa.

Lindón, A. (2008) Los giros de la geografía urbana: frente a la pantópolis, la microgeografía urbana. Scripta Nova. Revista Electrónica de Geografía y Ciencias Sociales, 270(62). Recuperado de http://www.ub.es/geocrit/sn/sn-270/sn270-62.htm

Lorimer, H. (2011) Walking: New Forms and Spaces for Studies of Pedestrianism. En Cresswell, T. y Merriman, P. (eds.), Geographies of Mobilities: Practices, Spaces, Subjects (pp. 19 - 34). Reino Unido: Ashgate

Lussault, M. (2015). El Hombre espacial. La construcción social del espacio humano. Madrid: Amorrortu.

Mairal Buil, G. (2000). La exploración etnográfica del espacio urbano. Revista de Antropología Social, 9, 177-191. Recuperado de https://revistas.ucm.es/index.php/RAS O/article/view/RASO0000110177A

Mansilla, P. (2018). Accesibilidad y movilidad cotidiana. En D. Zunino, G. Giucci, y P. Jirón (Eds.), Términos clave para los estudios de movilidad en América Latina (pp. 25-32). Buenos Aires: Editorial Biblos. 
Marosi, R. (6 de noviembre de 2017). Mexico's Housing Debacle. A Failed vision. Los Angeles Times. Recuperado de http://www.latimes.com/projects/lame-mexico-housing/.

Mason, J. (2002). Qualitative Researching. Londres: Sage.

Massey, D. (2006). For Space. Londres: Sage.

MiMorelia.com. (7 de noviembre de 2018). Municipio revisará factibilidad de crecimiento y servicios en Villas del Pedregal. Recuperado de https://www.mimorelia.com/municipio -revisara-factibilidad-de-crecimientoy-servicios-en-villas-del-pedregal/.

Noventa Grados. (8 de noviembre de 2018). Villas del Pedregal con mayor número de casos por violencia intrafamiliar. Recuperado de: http://www.noventagrados.com.mx/seg uridad/villas-del-pedregal-con-mayornumero-de-casos-por-violenciaintrafamiliar.htm.

Pedrotti, C. (2016). Calidad residencial y condiciones de producción de la vivienda social promovida por el sector privado. Zona Metropolitana de Toluca, 2001-2011. México: UNAM, PUEC, Infonavit.

Puebla, C. (2002). Del intervencionismo estatal a las estrategias facilitadoras. Cambios en la política de vivienda en México. México: El Colegio de México.

Puebla, C. (2010). El Estado y la promoción inmobiliaria de vivienda en México (Tesis Doctoral). Uniersidad Autónoma de México- Xochimilco, División de Ciencias Sociales y Humanidades, México.
Robert, K. (2018). Automovilidad. En D. Zunino, G. Giucci y P. Jirón (Eds.), Términos clave para los estudios de movilidad en América Latina (pp. 4148). Buenos Aires: Editorial Biblos.

SEDATU, y CONAVI. (2017). Código de Edificación de Vivienda. México: International Finance Corporation. World Bank Group. IFC; Organismo Nacional de Normalización y Certificación de la Construcción y Edificación.

Schteingart, M., y Patiño, L. (2006). El marco legislativo, programático e institucional de los programas habitacionales. En R. Coulomb y M. Schteingart (coords.), Entre el Estado y el mercado: la vivienda en el México de hoy (pp. 153 191). México: Miguel Ángel Porrúa/UAM-Azcapotzalco/Cámara de Diputados-LIX Legislatura.

Sheller, M. (2017). From spatial turn to mobilities turn. Current Sociology, 65(4), 623-639. doi: $10.1177 / 0011392117697463$.

Sheller, M. (2018). Mobility Justice: The Politics of Movement in an Age of Extremes. Londres: Verso.

Sheller, M., y Urry, J. (2016). Mobilizing the new mobilities paradigm. Applied Mobilities, 1(1), 10-25. doi: 10.1080/23800127.2016.1151216.

Sheller, M., y Urry, J. (2006). The new mobilities paradigm. Environment and Planning A., 38, 207-226. doi: 10.1068/a37268.

Spradley, J. P. (1980). Participant Observation. Nueva York: Holt, Rinehart and Winston.

Stock, M. (2001). Mobilités géographiques et pratiques des lieux. Étude théorico- 
empirique à travers deux lieux touristiques anciennement constitués: Brighton \& Hove (Royaume-Uni) et Garmisch-Partenkirchen (Allemagne) (Tesis doctoral). Université de Paris VII, París, Francia.

Stock, M. (2006). L'hypothèse de l'habiter poly-topique: pratiquer les lieux géographiques dans les sociétés à individus mobiles. EspacesTemps.net. Recuperado de https://www.espacestemps.net/en/articl es/hypothese-habiter-polytopique/.

Thomas, R. (2007). La marche en ville: Une histoire de sens. L'espace Geographique, 36(1), 15-26. doi: 10.3917/eg.361.0015.

Tironi, M. (2018). Introducción. Caminar como fenómeno social total. En M. Tironi, y G. Mora (Eds.), Caminando. Prácticas, corporalidades y afectos en la ciudad (pp. 15-33). Santiago de Chile: Ediciones Universidad Alberto Hurtado.

Tuan, Yi-Fu. (2007). Topofilia. Un estudio de las percepciones, actitudes y valores sobre el entorno. Santa Cruz de Tenerife: Melusina.

Urry, J. (2003). Social networks, travel and talk. British Journal of Sociology, 54(2), 155-175. doi: 10.1080/0007131032000080186.

Urry, J. (2007). Mobilities. Cambridge: Polity Press. 